\title{
SARAMPION INTERCURRENTE EN NIÑOS SOMETIDOS A TERAPIA CON CORTICOIDES
}

\author{
DrS. WERNER BUSTAMANTE, OSLAR ILLANES, JOSE LEGARRETA \\ Y MARCOS KIRBERG
}

\author{
Cátedra de Pediatría del Prof. A. Ariztia. \\ Hospital de Niños "I.uis Colvo Matkenna". Sanciago.
}

En el presente trabajo damos a conocer las observaciones que hemos reunido en el Hospital de Niños "Luis Calvo Mackenna" y que se refieren a la aparición del Sarampión, como enfermedad intercurrente, en niños hospitalizados y sometidos durante un tiempo prolongado con una terapia a base de corticoides.

A fínes de 1957 falleció en el Servicio de Infecciosos un lactante a consecuencia de un sarampión gravísimo complicado de bronconeumonía. En aquella oportunidad al comentar y discutir el caso en reunión anatomopatológica, planteamos entre otras cosas la posible participación que pudiera haber tenido en la gravedad del cuadro un tratamiento a base de cortisona recibido durante 13 dias consecutivos por un pénfigo (Obs. No 2 ). Durante esos días recibimos la visita del Prof. Dr. Raúl Vásquez, de Buenos Aires, quien casualmente nos informó acerca de dos casos fatales de sarampión en niños que se encontraban bajo tratamiento prolongado con corticoides.

Con estos antecedentes resolvimos precisar mejor este problema estudiando la literatura que estaba a nuestro alcance y revisando al mismo tiempo aquellas historias en que el sarampión hubiera aparecido durante un tratamiento con corticoides como enfermedad intercurrente.

Con respecto a esta materia, nos llamó la atención la escasez de referencias bibliográficas, no obstante de gran importancia nos pareció el trabajo de Nichols ', quién da a conocer 4 casos de sarampión en niños tratados con cortisona por distintas afecciones hematológicas, de los cuales fallece uno de ellos y los otros 3 se recuperan con dificultad. También incluye en su trabajo 3 niños con varicela, de los cuales 2 fallecen y otro se restablece normalmente. En su comentario expresa que los corticoides son responsables de la gravedad que experimentan los virus de tipo exantematosos. En cuanto a otras enfermedades virales exantemáticas, existen referencias de gran interés coma ser las que se relacionan con la varicela ${ }^{2 * 3} \mathrm{y}$ herpes zoster 4 .

Al revisar nuestro material logramos reunir 7 observaciones de niños sometidos a una terapia con corticoides quienes presentaron un sarampión como enfermedad intercurrente. De acuerdo con el diagnóstico de su enfermedad principal tenemos: 2 nefrosis; 2 meningitis tuberculosa; 1 pénfigo; 1 hepatitis y 1 caso de recituloendoteliosis.

Caso 1. - Obs. 64537. Niña de 2 años dè edad y 13.400 gr. de peso, ingres al Hospital el 21 de Ootube de 1957 con el diagnóstico de Reticulotndoteliosis (Letter Siwe). Como tratamiento tecibe una cura de meticortén durante 33 dias, empezando por 40 ngr. distros para if decreciendo paulatinamente hasta llegar a $20 \mathrm{mgt}$. por dia. Luego continúa con cortisona. 100 mgr. diarios por 4 días, con 3 de descanso. durante 9 semanus. Recibe antibióticos en la primera semana de meticortén $y$ después junto a cadx cura de cortisona, empleándose de peferencia actomicina o tertamicina, 100 mgr. cada 6 horas. La dosis total rccibida fué de $1.080 \mathrm{mgr}$. de meticortén y 3.200 mgr. de cottisona.

$A$ los 3 meses de tratamiento discontinuo con corticoides y acusando uns mejoría clinica de su teticuloendoteliasis, presenta un sarampión que adquicre caracteres de intensa gravedad, con gran compromiso del estado general desde sus primeros momentos. Rápidamente se complica con un proceso de tipo bronconeunotico y fallece bruscamente a los 10 dias de inirudo el sarangión. Dorante todo este periodo no st' suspende al tratamitento a bise de corticoides y acro. micina.

En la anatomia patológica se confirma cl diagnóstico de retículoendoteliosis y en sus pulmones se aprecian bulas de enfiscma, hiperemia acentuada y zonas de atclectasia difusa.

Caso 2, - Obs, 63416. Niña de 8 nicses de cdad v $6.900 \mathrm{gr}$. de peso, ingresa al Servicio de Infecciosos el $20 \mathrm{de}$ Septiembre de 1957 con el diagnóstico de Pintigo. Como tratamiento tecibe durante sus princ- 
ros días penicilina, estreptomicina, agregándose lucgo quentictina $\mathrm{y}$ cortisona, a razón esta última de 75 mgr. diarios, con un toral de $970 \mathrm{mgr}$, durante 13 dias.

Estando en convalecentia, sano de su pénfigo, prisenta un sarampión intercurtente a los 13 dias de iniciada su terapia con corticoldes, motivo por el cual se suspende la cortisona y queda en croupete con penicilina y estroptomicina.

El saranpión evoluciona en forma gravisima. complizindose desde un comienzo con bronioneumonia t. hipertermia mantenida, del cual fallece a los 6 dias de iniciado este proceso. En la anatomia patológica se confirma una desnutrición, secuela de píntigo y una bronconeumonia bilateral.

Caso 3. - Obs, 47291 . Niño de 1 año 3 meses de edad y 6.800 gr. de peso. ingresa al Hospital el 17 de Marzo de 1958 con los diagnósticos de Maningitis ruberculosa; Tubereulosis pulmonar fibrocosensa. Su trat:atmiento se realiza con estreptomicina, lidrazida y PAS. A los 2 meses y medio de tratamiento st' agtega una cura de meticortén a razón de $10 \mathrm{mgr}$. diarios, durante 1 mes 24 dias, recibiendo en total 540 mgr.

A los 20 dins de suspendido el tratamiento con torticoides $y$ sin obsirvarse una franca mejoria de su cuadro olínico. prosenta un sarampión intercurrente que evoluciona en forma grave desde cl comienzo. con gean biferternia y compromiso dil esrado general. Continúa con su tratamiento a base de estreptomicina e hidrazida, agregindose ademas penicilina sin resu!tado alguno, falleciendo a los 3 dias de inicindo al cuadro. en pleno priodo de exantema y complicado de bronconcumonia.

El estudio anatomopatológico reveló una meningitis tuberculosa fibrocaseosa; neumonía caseosa del lóbulo superior izquierdo: neumonia intersticial cn focos: peribronquitis: secuelas de tuberculosis en pulmón derecho.

Caso 4. - Obs. 61637. Niño tĩ ] año de cdid y $9 \mathrm{~kg}$. de peso. ingresa el $8 \mathrm{de}$ Agosro de 1957 con los diagnósticos de Meningitis tuberealosa y granulia. Su tratamiento sc bate con estreptomicitia. bidracida y PAS, agregandose además meticortón a tazón de 18 migr. diarios durante 7 dias; 15 mgr. por 14 dias y $7.5 \mathrm{mgr}$ por espacio de 11 dias. En total recibe $437 \mathrm{mgr}$. en 32 dias.

A tos 23 dias de tratamiento y obstrindose una franca recuperación clínica de su meningitis y granulia, presenta un sarampión de forma grave que se complica de laringitis obstructiva y bronconeumonia. Se continúa con su terapia inicial. ogregindose penicilina durante una scmanx. Г⿳亠 vista de su gravedad y los fenómenos obsituctivos que no ceden al calcibronat, croupette, etc., se hace una traqucotomia, sin resultado, falleciendo $\rightarrow$ los 9 dias de iniciaclo su sarampión.
En la nocropsia se comprueba una meningoancefajitis crónica con tendencia a la organización y calcificaión. Focos nodulares diseminadas sospechosas de secucfas tuberculosas. Zonas de cdema y hemortagin.

Caso 5, - Obs, 45891. Niña de 2 años 3 mses de edad y con $11.600 \mathrm{gr}$. de pesa, ingresa el 19 $^{2}$ de Fcbrero de 1958 al Hospital con el diagróstico de Hepatitis aguda. Como tratamiento recibe a su ingreso cortisona, $25 \mathrm{mgr}$. durante 4 días. reduciéndose la dosis después a cada 8 horas durante 2 dias. En total ingiere $550 \mathrm{mgr}$. en $\sigma$ dias $y$ terramizina durante el mismo período de tiempo.

Al cérmino de csta cura se observa una evidante mejoria clinica. Permanece 5 dias sin tratamiento, presentando posieriormente un sirampión que evolnciona en forma moderada durante 6 días, sin mayors consecuencias. Finalizado este proceso se reinicia una nueva cura ton meticortén por espacio de 30 dias. Los controles de laboratotios y una biopsia bepatica revelan posteriormente una cirrosis de tipo portal. lormanece 2 meses en el Servicio y es trasladado al Susañ Palma.

Caso 6. - Obs. 37002 . Niño de 2 años 10 meses de cdad y' $10 \mathrm{~kg}$. de peso. ingresa al Hospital ol 23 de Agosto de 1957 con el. diagnóstico de Nefrosis. Se trata con meticortén en curas discontinuas, injciándcse con 20 mgr. durante 10 dias, con 4 de descanso: luego una serie de curas alteraadas de 20 mgr. diarios por espacio de 4 dias y 4 de descanso, tratamiento que se arompaña de penicilina.

A: mes $y$ medio de iniciado este tratamiento 'y estando en buenas condiciones generales, con regresión clinica de su sintomatologia. presenta un sarampión por el cual se suspende de jnmediato el meticortén. después de baber recibido un toral de $460 \mathrm{mgr}$. quedando solamence con penicilina $y$ estreptomicina.

La cvolución seguida por st proceso samanpionoso dúó 8 dias y fué calulogado de tipo moderado. sín complicación alguna, motivo por el cual se rcinicia su clira con meticortén tan pronto pasin las manifestaciones agudas. Permanece 3 meses en el Servicio y es rasladada al Susana Palma.

En Marzo de 1958 reingresa por su siadrome nefrósico, recibiendo una curà de meticortén. $20 \mathrm{mgr}$. diarios por espacio de 25 dias. Cinco días despucs de fisalizar esta cura presenta uno varicela que evoluciona con caracteres moderados $y$ sin complicación. siendo dado de alta en buenas condiciones clinicas y gencrales 20 dias más tatde.

Caso 7. - Obsv. 28730 . Niño de" 2 años de edad y $12 \mathrm{~kg}$. de peso, ingresa al Hospital el 5 de. Maycs de $1956 \mathrm{con}$ el diagnóstico de Nefrosis. y Bronconeumonis. Recibe penicilina y mejora rápidamente do su cundro agudo pulmonar, Diez dias después se inicia 
su cuta con cortisona a tazón de $150 \mathrm{mght}$. durante 5 días: $100 \mathrm{mgr}$. por espario de 10 dias, para lusgo it disminuyendo cada 10 dias a razon de $75 \mathrm{mgt}$. $50 \mathrm{mgt}$ y $25 \mathrm{mgr}$. diarios.

A los 45 días de tratamiento con cortisena presenta an sarampión que evoluciona en forma moderad. sin complicaciones, durante 9 dias. Su teatumicnto sc sus. pende al quinto dia de enfermedad. quedando soía con aspirina. Posteriormente evoluciona sin molestias $y$ ex dado de alra en buenas condiciones clinicas y generales.

Reingrest por su sindrome nefrósico en Mirzo dc 1957, del cual recupera. En Abril de 1958 vuelve nucvamente por su nctrosis y se somete a dos cutas de 12 y 10 dias de meticortin. dosis variables de 25 mgr. diarios aproximadamenas, prescntando al rírmino de la segunda cura una varicels benigna que evolucions sin mayots contratiempos.

\section{COMENTARIO}

Al analizar en conjunto las 7 observaciones podemos ver que recibieron de preferencia meticortén y cortisona para el tratamiento de su enfermedad principal: nefrosis, meningitis tuberculosa, pénfigo, hepatitis y retículoendoteliosis. En 2 casos el tratamiento fué discontinuo (Obsv. 1 y 6); el resto recibió la droga en forma continuada por un total de días que fluctuó entre $6,13,32,45$ y 54 . (Obsv. $5,2,3,4$, y 7 ).

Debemos recalcar que antes de aparocer el sarampión intercurrente, 6 de nuestros enfermos se encontraban en condiciones clínicas satisfactorias (Obsv. 1, 2, $4,5,6$ y 7). Solamente uno de ellos (Obsv. 3 ) evolucionaba en forma estacionaria e irregular. Las dosis de corticoides hasta ese momento recibidas variaban entre 625 mgr.; 970 mgr.; 3.200 mgr. y 3.250 mgr.-de cortisona. En cuanto al meticortén, éste alcanzaba a $460 \mathrm{mgr}$, $540 \mathrm{mgr}$. y $610 \mathrm{mgr}$.

Es interesante anotar que en 2 casos se continúa el tratamiento con corticoides una vez aparecido el sarampión, falleciendo ambos (Obsv. 1 y 4). En los 5 casos restante 3 se suspende la droga en diferentes momentos, como ser: dos de ellos al iniciarse el sarampión (Obsv. 2 y 6); uno cinco días antes de empezar el cuadro (Obsv. 5); otro caso (Obsv. 3) se suspende 20 dias antes y en otro (Obsv. 7 ); se suspende a los 5 días de iniciado el sarampión. En este último grupo encontramos 2 fallecidos (Obsv. 2 y 3 ). Como ya hemos dicho, todos nuestros enfermos recibieron antibióticos durante los diferentas periodos de tiempo a que estuvieron sometidos con corticoides.

En cuanto a la evolución seguida por el sarampión, pudimos anotar que en 4 casos (Obsv. 1, 2, 3 y 4), el proceso adquirió caracteres de suma violencia y gravedad, con una duración de $10,6,3$ y 9 días. Hubo gran compromiso de su estado general, hipertermia mantenida o en agujas; complicaciones broncopulmonares desde un comienzo (Obsv. 1) o bien progresivas y con obstrucción respiratoria aguda que obligaron a una traqueotomía (Obsv. 4). Sólo en 3 casos el sarampión cvolucionó con caracteres clínicos modorados, sin complicaciones, durante $6.8 \mathrm{y}$ 9 días, tal fueron los dos casos de nefrosis y la hepatitis.

En cuanto a los resultados finales, yo hemos visto que fallecieron 4 enfermos (Obsv. 1, 2, 3 y 4 ), mejorando 3 de ellos (Obsv. 5,6 y 7). Es interesante mencionar el hecho que los 2 casos de nefrosis mejcrados reingresaron al Hospital algunos meses después por un nuevo episodio nefróticos, y al poco tiempo de estar con terapia a base de cortisona presentan una varicela que evoluciona sin mayores consecuencias.

Nuestra casuística es demasiado pequeña para sentar conclusiones por lo cual el verdadero significado de estas observaciones clínicas no podemos todavia precisarlas; no obstante creemos necesario llamar la atención acerca de estos hechos, especialmente entre los pediatras y servicics hospitalarios, donde es posible afrontar situaciones similares con mayor frecuencia, considerando el uso tan difundido que están adquiriendo estas drogas y la mayor o menor facilidad paro contraer enfermedades intercurrentes.

Nos hemos preguntado cuál habría sido la evolución de estos niños si no hubieran estado bajo el tratamiento hormonal al contraer su sarampión. Esta es una pregunta dificil de contestar ya que sils características clínicas y la imposibilidad de encontrar grupos controles similares no permiten juzgarlo con el frio criterio estadístico. Por el momento sólo un mayor número de observaciones clínicas $y$ los estudios experimentales pueden ayudarnos a contestar esta pregunta.

Con referencia al primer punto, ya hemos mencionado los casos relatados por 
Vásquez " en Argentina y Nichols ${ }^{1}$ en Estados Unidos. Además situaciones similares se están describiendo con otras enfermedades virales exantemáticas, como la varicela por Haggerty "; Shee" ; Nichols '. Uńa mayor divulgación de estos hechos nos va a permitir en un futuro evaluar en thejor forma este problema.

En cuanto a los trábajos experimentales estos cada día aumentan más. Debemos recordar que bajo ciertas condiciones la cortisona ha demostrado inhibir la formación de anticuerpos ${ }^{3 \cdot 4 \cdot 7-5}$; estimular y aumentar la cantidad de virus en los teJidos "s-y; acelerar el curso de la infeeción acortando el período de incubación ${ }^{\text {(s.t) }} \mathrm{y}$ favoreciendo la diseminación y extensión de la infección ${ }^{1+1}{ }^{\text {t1 }}$. En recientes publicaciones se viene demostrando el riesgo que presentan los corticoides frente a las infecciones virales activas o latentes. Los estudios experimentales con virus de Polio, Coxsakie, influenza, varicela y otros ${ }^{\text {k- }}$ $i-x, y$, son altamente estimulados por los corticoides, hecho que en clínica adquiere especial interés ya que no disponemos por el momento de un antibiótico eficaz y adecuado para protegernos de este grave compromiso:

El peligxo que presenta la terapia hormonal parece miayor cuando se usa en dosis grandes y per periodos largos de tiempo; puede a veces presentarse en tratamientos értos, pero el riesgo aesde al pútrito de vista clínico es más difícil de establecer.

Tófos nuestros enfermos han recibido corticoides por un espacio prolorgado de tiempo y en dosis variables, las cuales sin duda alguria deben de haber ínfluido en su sistema inmunitario y de defensa. El mecanismo exacto por el cual esta racacción a la infección se altera bajo el efecto de la cortisona o ACTH no está aun bien claro y se requiere mayor información. Sin embargo, Nichols ${ }^{1}$ procura dar una explicación al respecto cuando dica: "parece que los esteroides tienen muy poco efecto frente a la resistencia inmynobiólógica previamente; establecida. Esta propiedad, junto con la acción inhibidora del proceso inflamatorio constituyen la base de los éxitos obtenidos con cortisona en las encefalitis sarampionosas. En este caso el mecanismo inmurubiológico ha establecido previamente su acción $y$ es conveniente la cortisona para redu- cir la inflamación asociada. En cambio, cuando el proceso ocurre en pacientes que están bajơ terapia con corticoides el me. canismo inmunobiológico no se ha establecido $y$ es :probablemente modificado junto a la inhibición de la inflamación. predisponiendo a una posible generalización de la enfermedad, como seria el caso frente a la varicela u otras infecciones virales sin terapia específicas".

Expusimos el hecho que en dos casos la droga se suspendió antes de que : e! clínico sospechara la aparición del sarampión. y en uno de ellos alcanzó a 23 días: Se sabe al respecto que después de un prolongado periodo de tratamiento la corteza suprarrenal queda relativamente inastiva $\mathrm{y}$ atrófica por varios meses, según Chute ${ }^{\prime:}$. Estos estados loṣ interpreta Good como de hipoadrenalismo post-terapéutico, y relata un caso fatal después $f$ semanas que se había suspendido la cortisona. No obstante hay algunos hechos contradictorios en cuanto al restablecimiento de esta función, y es así como Chute ${ }^{1 \%}$ expresa que cuando la cortisona se ha dado por espacio mayor de 20 dias, la adrenocorticotropina intravenosa, $\mathrm{re}$ quiere 4 días para restablecer la actividad adrenal.

La evolución presentada por los dos cajos de nefrosis las consideramos interesantes, ya que el sarampión :en estos niźos tuvo un carácter moderado, sin com. plicaciones, y lo más llamativo es que ambos casos reingresaron algunos meses después nuevamente por su síndrome nefrósicos Sometidos a otra cura con corticoldes durante el tratamiento presentan una varicela intercurrenta, de evolución también moderada y con regresión tem poral de su nefrosis. Sin duda alguna que en el sindrome nefrósico deben de producirse bajo el efecto'de los corticoides cambios inmunobiológicos de tal magnitud que requieren mayor estudio para poder saber si en realidad el comportamiento del organismo en estos casos es diferonte.

En la hepatitis, que después evolúcionó hacia una cirrosis de tipo" portal, hubo también" un "comportamiento favorable. Sin embargo, hemos tenido conocimiento de otro caso de hepatitis aguda ${ }^{1:}$, tratada con cortisona que al mes de trata miento $y$ en pleno período de convalecencia adquiere un sarampión que evolu- 
ciona con caracteres de intensa gravedad. En este último caso no se suspendió la cortisona y se continuó hasta estar fuera de peligro.

De lo expuesto se plantea el hecho práctico que en ciertos casos y bajo condiciones aun no bien esclarecidas, el sarampión puede adquirir caracteres de intensa violencia y gravedad, si se presenta en un organismo sometido previamente a un tratamiento prolongado con corticoides.

Este problema adquiere especial relieve en los servicios hospitalarios donde es más posible encontrar niños sometidos a terapia prolongada con corticoides y expuestos a infecciones intercurrentes. Good ${ }^{1}$ sugiere como medida profiláctica el uso regular de gama globulina cada 2 semanas en aquellos casos que reciben cortisona y están expuestos a estas infecciones. Es posible que esta prevención pueda también lograrse con el uso del suero de convaleciente.

Lamentablemente no hay acuerdo acerca de como tratar a estos enfermos. Algunos autores ${ }^{1-2}$ sugieren disminuir las dosis de cortisona y llegar hasta el nivel del stress fisiológico, $25 \mathrm{mgr}$. por día y según sus necesidades. Otros prefieren suspenderla, según menciona Nichols ${ }^{1}$. Flẹischhacker ${ }^{14}$ considera que no debe de suspenderse la administración de la droga, por el contrario, habría que aumentarlas.

Frente a estos casos, creemos que la única manera de evitar las graves complicaciones que pueden presentarse con los corticoides radica en el hecho de que cada médico comprenda y reconozca que estas dirogas son potentes agentes farmacológicos, y usarlos por lo tanto cuando estén perfectamente bien indicados, después de evaluar los riesgos y beneficios a que expone al enfermo.

\section{RESUMEN}

En un período de 3 años los autores logran reunir 7 casos de sarampión intercurrente en niños hospitalizados. y bajo tratamiento prolongado con corticoides por diferentes afecciones: meningitis tuberculosa, nefrosis, pénfigo, hepatitis, reticuloendoteliosis. Seis de estos casos se encontraban en condiciones clínicas satisfactorias antes de aparecer el sarampión.
De los 7 enfermos, 4 fallecen durante la evolución del sarampión, que adquiere caracteres de suma violencia y gravedad. En los 3 casos restantes el sarampión fué de evolución moderada, lramando la atención el comportamiento observado en dos casos de nefrosis.

Los autores consideran que se requiere mayor estudio para poder apreciar el verdadero significado del problema; no obstante y de acuerdo con sus observaciones, plantean el hecho práctico de que en ciertos casos, y bajo condiciones aun no bien esclarecidas, el sarampión puede adquirir caracteres de suma gravedad si se presenta en un organismo previamentc sometido a un tratamiento prolongado con corticoides.

\section{SUMMARY}

INTERCURRENT MEASLES IN CHLLDREN UNDER A LONG TERM THEATMENT WITH CORTICOESTEFOIDS.

Seven cases of intercurrent measles in hospitalized children and under a long term treatment with corticoesteroids for differents diseases as nephrosis, Tbc. meningitis, penphigus, hepatitis, and Letterer Siwe, are presented.

In six cases general and clinical condition was good before measles appeared. Four deaths are reported during a severe clinical course of the viral infectious; three cases recovered after having a mild disease, among these were two cases of nephrosis.

The authors considered that more studies are needed to evaluate this problem, however they stress the fact that measles, in some cases not well elucidate, can have a severe clinical course in an organism under a long term treatment with corticoesteroids.

\section{BIBLIOGRAFÍA}

1.-NICHOLS, W. W. - Experiences with chickenpox in patients with hematologic diseases reclving cortisone. Jour, of Dis, of Chlld. 94:219, 1957.

2.-HAGGGRTY. R. J*t ELEY, R. C, - Varicella and cortisone. Pedistrica, 18:160, 1956.

3. SHEF, J, C.; FEEESN, F, - Reactivation of Varlcella virus by cortisone therapy. Brit. Med. Jour. 2:82, 1953 .

4. $-G O O D, \mathbf{R}$; VERNIER, R. y SMTH, $\mathbf{R}_{+}-$serious untoward resctions to therapy with cortisone and adrenocorticotrophin in pediatric practice. Pediatrlcs. I. I9:95. II, 18:272, 1957.

3.-VAsQUiz, R. - Comunieación personal.

6.- SCHWARTZMAN, $G$. Embancing effect of cortisone upon poliomyelitis infection (strain MaF- 
1) In hamsters and mice. Proc. Soc. Exper. Blol. \& Med. 75:835, 1950 .

7.-EH.BOURNE, E. D. - The influence of cortisone on expermental viral Infections. Jour. Immunol. $74: 57,1955$.

8.-KILEOURNE, E. D. - The Influence of cortisone on experimental viral infection. Inhibition of influenza virus. Jour. Fhx. Med, 106:833, 1957 .

8. -FINDLAY. C. M. Y HOWARD, E. M. - The effect of cortisone and adrenocortlcotrophic hormones on pollomyelitis and other virus infectlons. Jour. pharm. \& Pharmacol. 4t:37, 1952.

10.-THOMAs, L. - Infectious diseases; the effects of cortisone end adrenocorticotrophic hormone on Infection. Ann. Rev. Med. 31;1, 1952.

11.-THOMAS, I. - Cortisone and Infection. Ann. New York Acad. Sc. 56:799, 1953.

12. - CHUTR, A. L - Some complicatlons of transfuston, endocrine therapy and oxygen adminlstration. Pedlatrics. $22: 170$, 1958 .

13.-MONTERO, R. - Comunlcacion personal

14.-FLEISCFHACKER, H. - Terapética de las hemopatias, enfertnedades infecciosas, afeccionea cardjacas y vasculares con cortisona. Fco Médtco. E. Merck. Darmstadt. 1:I, 1958.

\section{DISCUSIÓN}

Prof. Steeger: Considera interesante el planteamiento que hacen los autores acerca del tema, pero estima que es difícil poder sacat conclusiones ya que el sarampión es una enfermedad grave en los niños menores de 3 años. Desea saber si han observado modificación $\mathrm{du}$ rante el periodo de incabación, pre-exantemático y exantemático, y si estos niños corresponden al mismo año o sea al mismo genio epidémico.

Dr. Del Pozo: Se refiere al distinto comportamiento que presentan los casos de nefrosis. Relata una revisión hecba en 11 casos de esta enfermedad tratada con meticortén en que dos casos presentan sarampión. los cuales evolucionan en buena forma. Esto estaria de acuerdo con lo observado por los autores.

Dr. Montero: Manifiesta que el sarampión frena la pérdida de gama gjobulinass en los nefróticos. Por otra parte los corticoides favorecen la generalización de los virus. Relata un caso de sarampión muy grave y violento en una chica que se encontraba bajo tratamiento prolongado con corticoides y que mejoró. Crec que debe de subirse la dosis de corticoides cuando aparece el sárampión en estas circunstancias.
Dr. Cid: Analiza la acción de los corticoides y en especial se refiere a la baja de la inmanidad que se produce en tratamiento prolongado donde el médico debe de estar alerta. Estima que frente a cualquier "stress" se debe de suibix la dosis para evitar la falla brusca de la saprarenal.

Dr. Recchione: Considera que ta casuistica es pequeña para sacar conclusiones. El problema de los corticoides frente a las infecciones es demasiado compirjo Y la gravedad ea la uvolución de los enfertios presentados puede explicarşe también sin necesidad dc recurrir a esta droga.

Dr. Kirberg: Desca rezordar que los enfermos presencades, a excepción de uno, se encontraban en buepas. condiciones clinicas cuando contrajeron el sarampión. Cree que los corticoides pueden usarse en las enfermedades infectiosas siempre que se agregue on antibiorico especifico, tal como sucede en el tratamiento de la tuberculosis, tifoidea, Desgraciadamente no hay por el momento antibióticos específicos contra el sarampión; motivo por el cual debe tenerse cuidado en las curas prolongadas con corticoides y prevenir a tiempo la infección viral intercurrente sarampionosa.

Dr. Bustanante: Manifiesta que en ningún momento han pretendido sacar concinsiones debide a que los casos reunidos en los últimos 3 años son todavía pocos. por este motivo, y así lo bicieron resaltar en la presentación, solo los ha guiado el animo de llamar la atención acerca de estos hechos observados y conocer la experiencia en esta materia de los otros colegas $y$ hospitales. Contestando at De. Steeger expresa que Jos niños corresponden a distintas epidemias y solo dos casos al año 1958. En cuanto a los datos referentes a periodos de incrbación, pre-eruptivo, etc., no han podido consignarlo en el estudio debido a la dificultad en precisar el momento exacto del contagio. datos que fajtan o están incompletos en las fichas clinicas. 